\title{
SCIDOC
}

\author{
International Journal of Dentistry and Oral Science (IJDOS) \\ ISSN: 2377-8075
}

\section{Incidence of Maxillofacial Trauma and Its Management - A Retrospective Study}

Research Article

Subhashini $\mathrm{R}^{1}$, Abdul Wahab PU²*, Santhosh Kumar MP³

${ }^{1}$ Saveetha Dental College and Hospitals, Saveetha Institute of Medical and Technical Sciences, Saveetha University, Chennai, India.

${ }^{2}$ Professor, Saveetha Dental College and Hospitals, Saveetha Institute of Medical and Technical Sciences, Saveetha University, Chennai, 600077, India.

${ }^{3}$ Reader, Saveetha Dental College and Hospitals, Saveetha Institute of Medical and Technical Sciences, Saveetha University, Chennai, 600077, India.

\section{Abstract}

\begin{abstract}
Maxillofacial trauma occurs in a significant proportion worldwide. It can occur as an isolated injury or in combination with other injuries like Cranial, Spinal, Extremities and Abdomen. The aim of this study was to evaluate the pattern, incidence, etiology and the treatment modalities for maxillofacial injuries. The medical records of all patients from July 2019 to March 2020 from hospital were retrieved, data extracted, tabulated and analysed. Statistical analysis was done for demographic data, pattern, site of injury and management with the SPSS software (version 20.0; SPSS, Chicago, IL, USA) and results obtained. Our study revealed that the main etiology of the maxillofacial injuries was found to be road traffic accidents $(\mathrm{p}<0.03)$ followed by assault. Males sustained more injuries $(85.9 \%)$ than females. Mandible was the most commonly injured site $(53.8 \%)$ followed by dentoalveolar fractures $(23 \%)$, Zygomaticomaxillary complex (ZMC) fractures $(10 \%)$, Naso-orbitoethmoid fractures (NOE) $(2 \%)$, and Panfacial fracture $(1 \%)$. In our study $33 \%$ of maxillary and condylar fractures were managed by Closed reduction and $67 \%$ of fractures were managed by Open reduction. Open reduction and internal fixation was the preferred treatment modality and the results were statistically significant $(p<0.01)$ From our study we can conclude that road traffic accidents were the most common cause for maxillofacial injuries, males were more affected and mandible was the commonly fractured site. Although the majority of cases were treated successfully by Open reduction and internal fixation, closed reduction can be done wherever indicated.
\end{abstract}

Keywords: Maxillofacial Trauma; Mandibular Fractures; Midface Fractures; Facial Injuries; Fixation.

\section{Introduction}

Injury to the facial structures is disastrous and it affects the quality of life; which increases the demand for esthetics [1,2]. Management of injuries in this region presents one of the most challenging procedures, as fractures are invariably associated with morbidity, disfigurement, functional problem and expensive treatment $[3$, 4].

Maxillofacial injury can be an isolated injury or can occur in combination with other injuries as well $[5,6]$. Road traffic accidents (RTA) are the common cause for the injury [7,8]. The aim of this retrospective study was to evaluate the incidence, gender prevalence, etiology, site of maxillofacial fractures and their management.

Face being the basic foundation of identity of an individual and it plays an important role in social approach-reception-appreciation. In fact the whole perspective of life turns dynamic with an esthetic face while facial deformity caused by trauma, congenital disabilities, and postsurgical sequelae produce a negative impact on perceptions of social functionality.

Maxillofacial injury is one of the most commonly involved components in the medical emergency and is the major case of death $[9,10]$. It can affect both skeletal and soft tissue components of the facial structures and proper management is necessary to meet their functional needs [11, 12]. Management of the injuries requires skill and experience $[13,14]$.

\section{Materials and Methods}

In this retrospective study, records of all the trauma patients reported and treated in the Department of oral and maxillofacial

*Corresponding Author:

Abdul Wahab PU,

Professor, Saveetha Dental College and Hospitals, Saveetha Institute of Medical and Technical Sciences, Saveetha University, Chennai, 600077, India.

E-mail: abdulwahab@saveetha.com

Received: October 07, 2020

Accepted: November 22, 2020

Published: November 25, 2020

Citation: Subhashini R, Abdul Wahab PU, Santhosh Kumar MP. Incidence of Maxillofacial Trauma and Its Management - A Retrospective Study. Int J Dentistry Oral Sci. 2020;7(11):1054-1057. doi: http://dx.doi.org/10.19070/2377-8075-20000208

Copyright: Abdul Wahab PU ${ }^{\odot}$ 2020. This is an open-access article distributed under the terms of the Creative Commons Attribution License, which permits unrestricted use, distribution and reproduction in any medium, provided the original author and source are credited. 
surgery, saveetha dental college and hospital, saveetha university, chennai between July 2019 and March 2020 were retrieved from hospital records. All patients with maxillofacial injuries were included in our study. Got Ethical clearance from the college ethical committee and the ethical clearance number is SDC/ SIHEC/2020/DIASDATA/0619-0320.

The records of 78 patients were retrieved. Data including demographic data, etiology of trauma, site of fracture and their management were extracted. Fractures were grouped as Mandibular fractures, midface fractures, zygomaticomaxillary fractures, nasoorbitoethmoid fractures, and Dentoalveolar fractures. Data was retrieved, tabulated and statistical analysis was performed using the SPSS software (version 20.0; SPSS, Chicago, IL, USA) and results obtained. Categorical variables were expressed as frequency and percentage; continuous variables as mean and Standard deviation. The chi-square test was used to test the association between the categorical variables. $\mathrm{P}$ values $<0.05$ were considered statistically significant.

\section{Results and Discussion}

In our study, out of 78 patients, 67 were males $(85.9 \%)$ and 11 were females $(14.1 \%$ ) who were affected by trauma. (Figure 1); Mean Age and SD of the patients was 30.45 \pm 11.95 with the age range of $4-67$ years. Our study revealed that main etiology of the maxillofacial injuries was found to be RTA $(p<0.03)$ followed by assault. Mandible was the most commonly injured site $(53.8 \%)$ (Figure 2), followed by dentoalveolar fractures $(23 \%)$, Zygomaticomaxillary complex (ZMC) fractures (10\%), Naso-orbitoethmoid fractures (NOE) (2\%), and Panfacial fracture (1\%). In our study $33 \%$ of maxillary and condylar fractures were managed by Closed reduction and $67 \%$ of fractures were managed by Open reduction and the results were statistically significant
$(p<0.01)$.(Figure 2). In our study we found that Open reduction and Internal Fixation (ORIF) was the preferred method for treating these injuries except for dentoalveolar fractures and few isolated condylar fractures for which closed reduction with Intermaxillary fixation (IMF) was done.

Trauma to maxillofacial regions requires special attention because of their proximity to the vital structures. So thorough evaluation is mandatory during primary stages of treatment. Etiology of trauma varies from one region to another along with various age groups. RTA is the leading cause of maxillofacial injury in developing countries and Assault in developed countries $[15,16]$. The common reason for RTA includes improper or no licensing, not wearing helmets, violating traffic rules, poor road facilities and so on $[17,18]$. Other causes include fall from height, domestic violence, animal bite etc. Our study showed significant association with RTA. In our study data, we have not encountered fall from height or animal bites as the etiology of maxillofacial injuries in this duration of nine months.

Several studies have shown male predominance in maxillofacial injuries as they are most commonly involved in outdoor activities, traveling, sports, driving and alcohol addiction [19-22]. In our study also males were affected more $(85.9 \%)$ than females $(14.1 \%)$. According to our study, the most common distribution of occurrence of trauma was between the $2 \mathrm{nd}$ and $4^{\text {th }}$ decade of life which is in accordance with the previous literatures [23-26].

In our study gross distribution of facial injury showed, mandibular fractures were more common $(53.8 \%)$ followed by Dentoalveolar fractures (23\%), ZMC (10\%), NOE (2\%) Panfacial trauma (1\%). Similar results were shown by previous studies [27, 28]. However in a study it was observed that midface fractures were more common, especially ZMC fractures [24]. Several studies [29, 30] stated

Figure 1. Pie Chart diagram showing gender wise distribution of maxillofacial traumas. There is a male predominance with $85.7 \%$ than females with $14.29 \%$.

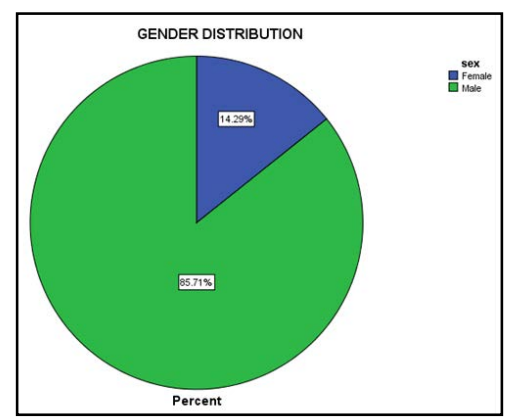

Figure 2. Bar graph depicting association between site of fracture and method of treatment where Green colour represents Mandibular fracture, X-Axis represents the Treatment done and Y-Axis represents the site of fracture. Mandible is the commonly involved Site and ORIF is the preferred treatment modality. Chi square value- $51.595 \mathrm{p}=0.01$ and hence it is statistically significant.

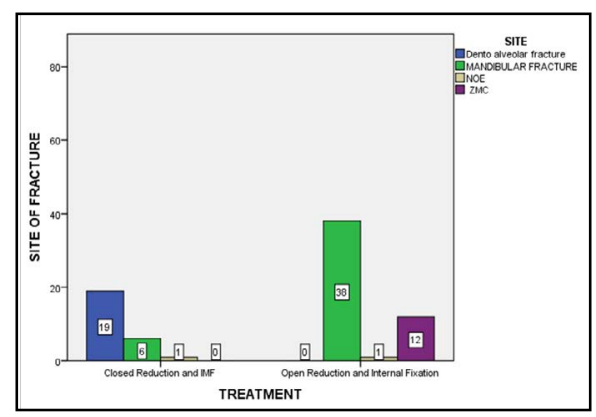


that trends and patterns in maxillofacial trauma are changing and it is increasing with RTA and assault.

In our study, following mandibular fractures, ZMC is the next common fracture which involves Zygomatic buttress, Zygomatic arch $(10 \%)$ and the results were in accordance with other studies [31].

Management of maxillofacial injuries is a real challenge to the surgeons and it needs skill and experience. The injury may vary from nasal fracture to communition of facial bones. Management is challenging because of the high vascularity and it is complicated by the vital structures like upper airway, cranial structures and cervical spine. Initial assessment includes [14] Airway, breathing, circulation, bleeding were done. Upper airway [32, 33] can be obstructed by severe midface, nasal complex and bilateral parasymphysis fracture. Assessment of cervical spine is important in initial evaluation in maxillofacial trauma patients.

Various treatment modalities for fracture management are conservative management, closed reduction with intermaxillary fixation (IMF) or open reduction and internal fixation (ORIF). Conservative management is done for undisplacedmidface without any functional or neurological involvement. It includes advising on a soft diet, analgesics, restricted mouth opening etc. Closed reduction is done for condylar fractures, single linear fractures with mild occlusal disturbance. It is done by using an arch bar and manual reduction followed by the IMF for 4-6 weeks. Problems with closed reduction with the IMF includeS difficulty in eating, and social inconvenience. Open reduction and Internal fixation is done for severe displacement of fractures, severe occlusal disturbances, and unstable ZMC fractures under general or local anaesthesia. It is accomplished with $1.5 \mathrm{~mm}$ or $2 \mathrm{~mm}$ Titanium or Stainless plates. Disadvantages include hospital stay, nerve injury, surgical complications, and cost. In our study $33 \%$ of maxillary and condylar fractures were treated by Closed reduction and majority $(67 \%)$ of fractures were treated by Open reduction and internal fixation (ORIF).

\section{Conclusion}

From our study we can conclude that road traffic accidents were the most common cause for maxillofacial injuries, males were more affected and mandible was the commonly fractured site. Although the majority of cases were treated successfully by Open reduction and internal fixation, closed reduction can be done wherever indicated.

\section{References}

[1]. Zargar M, Khaji A, Karbakhsh M, Zarei MR. Epidemiology study of facial injuries during a 13 month of trauma registry in Tehran. Indian J Med Sci. 2004 Mar;58(3):109-14.Pubmed PMID: 15051905. https://pubmed.ncbi. nlm.nih.gov/15051905/

[2]. Abhinav RP, Selvarasu K, Maheswari GU, Taltia AA. The Patterns and Etiology of Maxillofacial Trauma in South India. Ann Maxillofac Surg. 2019 Jan-Jun;9(1):114-117.Pubmed PMID: 31293938.

[3]. Rana ZA, Khoso NA, Arshad O, Siddiqi KM. An Assessment of maxillofacial injuries: A 5-year study of 2112 patients. Ann Pak Inst Med Sci. 2010;6(2):113-5.

[4]. Sweta VR, Abhinav RP, Ramesh A. Role of Virtual Reality in Pain Perception of Patients Following the Administration of Local Anesthesia. Ann Maxillofac Surg. 2019 Jan-Jun;9(1):110-113.Pubmed PMID: 31293937.

[5]. Emshoff R, Schöning H, Röthler G, Waldhart E. Trends in the incidence and cause of sport-related mandibular fractures: a retrospective analysis. J Oral Maxillofac Surg. 1997 Jun;55(6):585-92.Pubmed PMID: 9191640.

[6]. Jesudasan JS, Wahab PU, Sekhar MR. Effectiveness of $0.2 \%$ chlorhexidine gel and a eugenol-based paste on postoperative alveolar osteitis in patients having third molars extracted: a randomised controlled clinical trial. $\mathrm{Br} \mathrm{J}$ Oral Maxillofac Surg. 2015 Nov;53(9):826-30.Pubmed PMID: 26188932.

[7]. Akama MK, Chindia ML, Macigo FG, Guthua SW. Pattern of maxillofacial and associated injuries in road traffic accidents. East Afr Med J. 2007;84(6):287-95.

[8]. Santhosh Kumar MP, Sneha S. Knowledge and awareness regarding antibiotics prophylaxis form for infective endocarditis among under graduate dental students. Asian J Pharm Clin Res. 2016;9(2):154-9.

[9]. Gassner R, Tuli T, Hächl O, Rudisch A, Ulmer H. Cranio-maxillofacial trauma: a 10 year review of 9,543 cases with 21,067 injuries. J Craniomaxillofac Surg. 2003 Feb;31(1):51-61.Pubmed PMID: 12553928.

[10]. Rao TD, Kumar MP. Analgesic Efficacy of ParacetamolVs Ketorolac after Dental Extractions. Res J Pharm Technol. 2018;11(8):3375-9.

[11]. Dibaie A, Raissian S, Ghafarzadeh S. Evaluation of maxillofacial traumatic injuries of forensic medical center of Ahwaz, Iran, in 2005. Pak J Med Sci. 2009 Jan 1;25(1):79-82.

[12]. Kumar S, Rahman RE. Knowledge, awareness, and practices regarding biomedical waste management among undergraduate dental students. Asian J Pharm Clin Res. 2017;10(8):341-5.

[13]. Perry M. Maxillofacial trauma--developments, innovations and controversies. Injury. 2009 Dec;40(12):1252-9.Pubmed PMID: 19486969.

[14]. Rahman R, Mp SK. KNOWLEDGE, ATTITUDE, AND AWARENESS OF DENTAL UNDERGRADUATE STUDENTS REGARDING HUMAN IMMUNODEFICIENCY VIRUS/ACQUIRED IMMUNODEFICIENCY SYNDROME PATIENTS. Asian J Pharm Clin Res [Internet]. 2017;10(5):175-80.

[15]. Bali R, Sharma P, Garg A, Dhillon G. A comprehensive study on maxillofacial trauma conducted in Yamunanagar, India. J Inj Violence Res. 2013 Jul;5(2):108-16.Pubmed PMID: 23594725.

[16]. Packiri S, Gurunathan D, Selvarasu K. Management of paediatric oral ranula: a systematic review. J. Clin. Diagnostic Res. 2017 Sep;11(9):ZE06-9.

[17]. Udeabor S, Akinmoladun VI, Olusanya A, Obiechina A. Pattern of midface trauma with associated concomitant injuries in a nigerian referral centre. Niger J Surg. 2014 Jan;20(1):26-9.Pubmed PMID: 24665199.

[18]. Patturaja K, Pradeep D. Awareness of Basic Dental Procedure among General Population. Res J Pharm Technol. 2016;9(9):1349-51.

[19]. Septa D, Newaskar VP, Agrawal D, Tibra S. Etiology, incidence and patterns of mid-face fractures and associated ocular injuries. J Maxillofac Oral Surg. 2014 Jun;13(2):115-9.Pubmed PMID: 24822001.

[20]. Mohan D. Traffic Injuries and Fatalities in India. Transportation Research \& Injury Prevention Programme, IIT Delhi. 2004 Apr.

[21]. Jagnoor J, Keay L, Ivers R, Suraweera W, Jha P. Unintentional injury mortality in India, 2005-estimates from a nationally representative mortality survey of 1.1 million homes. Inj Prev. 2010 Sep 1;16(Suppl 1):A68-9.

[22]. Kumar S. Relationship between dental anxiety and pain experience during dental extractions. Asian J Pharm Clin Res. 2017;10(3):458-61.

[23]. Chrcanovic BR, Abreu MH, Freire-Maia B, Souza LN. 1,454 mandibular fractures: a 3-year study in a hospital in Belo Horizonte, Brazil. J Craniomaxillofac Surg. 2012 Feb;40(2):116-23.Pubmed PMID: 21458284.

[24]. Singaram M, G SV, Udhayakumar RK. Prevalence, pattern, etiology, and management of maxillofacial trauma in a developing country: a retrospective study. J Korean Assoc Oral Maxillofac Surg. 2016 Aug;42(4):174-81. Pubmed PMID: 27595083.

[25]. Kumar S. The emerging role of botulinum toxin in the treatment of orofacial disorders: literature update. Asian J Pharm Clin Res. 2017;10(9):21.

[26]. Patil SB, Durairaj D, Suresh Kumar G, Karthikeyan D, Pradeep D. Comparison of Extended Nasolabial Flap VersusBuccal Fat Pad Graft in the Surgical Management of Oral Submucous Fibrosis: A Prospective Pilot Study. J Maxillofac Oral Surg. 2017 Sep;16(3):312-321.Pubmed PMID: 28717289.

[27]. Pandey S, Roychoudhury A, Bhutia O, Singhal M, Sagar S, Pandey RM. Study of the pattern of maxillofacial fractures seen at a tertiary care hospital in north India. J Maxillofac Oral Surg. 2015 Mar;14(1):32-9.Pubmed PMID: 25729224.

[28]. Ansari MH. Maxillofacial fractures in Hamedan province, Iran: a retrospective study (1987-2001). J Craniomaxillofac Surg. 2004 Feb;32(1):28-34. Pubmed PMID: 14729047.

[29]. Erol B, Tanrikulu R, Görgün B. Maxillofacial fractures. Analysis of demographic distribution and treatment in 2901 patients (25-year experience). J Craniomaxillofac Surg. 2004 Oct;32(5):308-13.Pubmed PMID: 15458673.

[30]. Marimuthu M, Andiappan M, Wahab A, Muthusekhar MR, Balakrishnan A, Shanmugam S. Canonical Wnt pathway gene expression and their clinical correlation in oral squamous cell carcinoma. Indian J Dent Res. 2018 MayJun;29(3):291-297.Pubmed PMID: 29900911. 
[31]. Naveen Shankar A, Naveen Shankar V, Hegde N, Sharma, Prasad R. The pattern of the maxillofacial fractures - A multicentre retrospective study. J Craniomaxillofac Surg. 2012 Dec;40(8):675-9.Pubmed PMID: 22212823.

[32]. Vijayakumar Jain S, Muthusekhar MR, Baig MF, Senthilnathan P, Loganathan S, Abdul Wahab PU, et al. Evaluation of Three-Dimensional Changes in Pharyngeal Airway Following Isolated Lefort One Osteotomy for the Correction of Vertical Maxillary Excess: A Prospective Study. J Maxillofac Oral
Surg. 2019 Mar;18(1):139-146.Pubmed PMID: 30728705.

[33]. Christabel A, Anantanarayanan P, Subash P, Soh CL, Ramanathan M, Muthusekhar MR, et al. Comparison of pterygomaxillarydysjunction with tuberosity separation in isolated Le Fort I osteotomies: a prospective, multi-centre, triple-blind, randomized controlled trial. Int J Oral Maxillofac Surg. 2016 Feb;45(2):180-5.Pubmed PMID: 26338075. 